\title{
Geometry and Kinematics of Experimental Antiformal Stacks
}

\author{
CAROLINE JANETTE SOUZA GOMES and JULIANO EFIGÊNIO FERREIRA \\ Departamento de Geologia, Universidade Federal de Ouro Preto \\ 35400-000 Ouro Preto, Minas Gerais, Brasil \\ Manuscript received on July 16, 1999; accepted for publication on November 9, 1999; \\ presented by IGOR I. GIL PACCA
}

\begin{abstract}
Sandbox experiments with different boundary conditions demonstrate that antiformal stacks result from a forward-breaking thrust sequence. An obstacle blocks forward thrust propagation and transfers the deformation back to the hinterland in a previously formed true duplex. In the hinterland, continued shortening causes faults to merge toward the tectonic transport direction until the older thrusts override the younger thrusts. In experiments using thin sand layers or high basal friction, shortening is accommodated by a cyclic process of thrusting, back rotation of the newly formed thrust combined with strong vertical strain, and nucleation of a new thrust. Continuous deformation produces an antiformal stack through progressive convergence of branch lines.
\end{abstract}

key words: basement structures, slightly dipping basal detachment, sand layer thickness, basal friction.

\section{INTRODUCTION}

Physical modelling has been used with success to investigate the mechanical and kinematic evolution of structures and deformational systems. For example, Davis et al. (1983) and Dahlen et al. (1984) have proposed the critical taper model based on mathematical calculations and demonstrated its validity using sandbox modelling. Marshak et al. (1992) have discussed the formation of curved thrust belts using analogue models. McClay \& Ellis (1987), McClay (1990) and McClay \& Scott (1991) have presented scaled sandbox models of extensional structures to illustrate the tectonic evolution of sedimentary basins.

Thrust system geometries were described by Bally et al. (1966), Dahlstrom (1969) and Boyer \& Elliott (1982). Boyer \& Elliott (1982) published a

Correspondence to: Caroline Janette Souza Gomes

E-mail: caroline@degeo.ufop.br classification and an evolutionary tectonic model for these contractional sequence. Mitra (1986) introduced the concept of "overlapping ramp anticlines", based on the amount of shortening accommodated by the thrust systems. Mitra's classification distinguishes a foreland sloping duplex, consisting of partly overlapping anticlines, from an anticlinal stack, consisting of completely overlapping anticlines. McClay (1992) defined antiformal stacks as systems of totally overlapping thrust horses characterized by a coincident trailing branch line (Fig. 1).

The purpose of this paper is to investigate, using physical models, why antiformal stacks form instead of independent ramp anticlines or true duplexes. The 'independent ramp anticlines' were described by McClay (1992) as systems "were the final spacing between the thrusts is much greater than the displacement on the individual thrusts and the struc- 


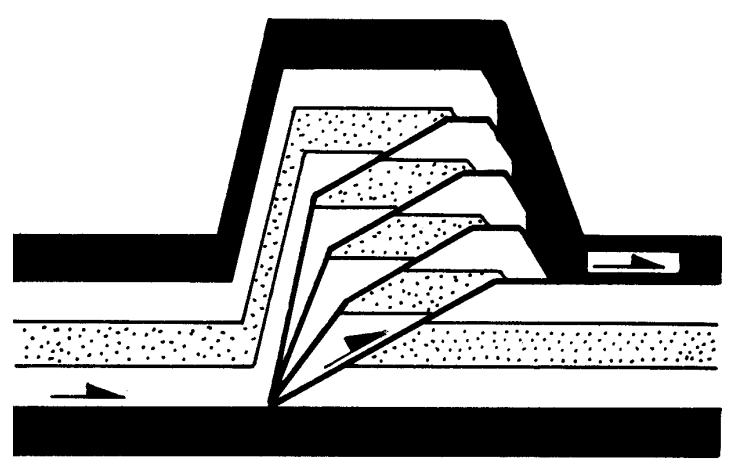

Fig. 1 - An antiformal stack according to McClay (1992).

ture formed consists of independent ramp anticlines separated by broad synclines", and the "true duplexes', as "a particular combination of final thrust spacing, ramp angle and ramp height such that parts of all the link thrusts and roof thrusts are parallel to the frontal ramp of the duplex". The characteristic feature of true duplexes is the presence of at least two branch lines: a trailing branch line and a leading branch line. In antiformal stacks, due to the increasing displacement of individual ramp anticlines, those branch lines coincide (McClay, 1992). This study concerns the mechanical constraints that permit, in a primary built duplex, that trailing branch lines gather together before a new thrust arises in the foreland. In addition, it also investigates the process involved in thrust horses overriding one another.

Although anticlinal stacks have been described by many authors, no study on the mechanics controlling their development has yet been conducted. For example, Jadoon et al. (1992) described antiformal stacks in a fold belt in Pakistan and attributed their formation to a detachment, having a $2.5^{\circ}$ slope (Fig. 2). Using a balanced cross-section, Muñoz (1992) presented a basement-involved antiformal stack in the axial zone of the Pyrenean continental collision belt (Fig. 3).

In this paper, we present a series of sandbox analogue experiments to investigate the evolution of antiformal stacks in a thrust system. The boundary conditions described by Jadoon et al. (1992) and
Muñoz (1992), i.e. a slightly dipping basal detachment and control by basement structures, respectively, are also examined. We have introduced some variables concerning the geometry of pre-existing basement structures (herein, referred to as "obstacle"), initial sand layer thickness and basal friction. The study of the different obstacle geometries has the purpose of highlighting the kinematic evolution of antiformal stacks. The variations in layer thickness and in the degree of basal friction are to investigate possible effects over the antiformal stack geometry.

Physical models permit direct observation of analogs for evolving geological structures. Thus, they may allow observation of structures and processes not yet recognized in nature. The correlation between models and nature presents some difficulties due to the insufficient knowledge on the complex rheologic properties of deforming rocks. Moreover, simulation of the earth's crust in sandboxes requires the entire continental crust to be treated as a continuous medium with homogeneous properties. Thus, small-scale variations in the mechanical properties of rocks, compaction of sediments and thermal perturbations cannot be considered. Even with those difficulties, simulations provide valuable insights into the development of thrust systems and, in particular, of antiformal stacks, for which theoretical and experimental tectonic models are not available.

\section{EXPERIMENTAL METHODS AND PROCEDURE}

In our models, the brittle, upper continental crust was simulated using carefully sieved and dyed quartz sand $(200-300 \mu \mathrm{m})$ from the alluvial Itacolomi Quartzite (Ouro Preto, Minas Gerais). Dry sand, widely used as an analogue for rocks from the upper continental crust, has an internal friction angle of $30^{\circ}$ and fails according to a Navier-Coulomb law. Length scaling between the physical model and the natural prototype follows the theory described by Hubbert (1937) and discussed by Vendeville et al. (1987) and McClay \& Ellis (1987). Hubbert (1937) demonstrated that to set up models "as similar as 


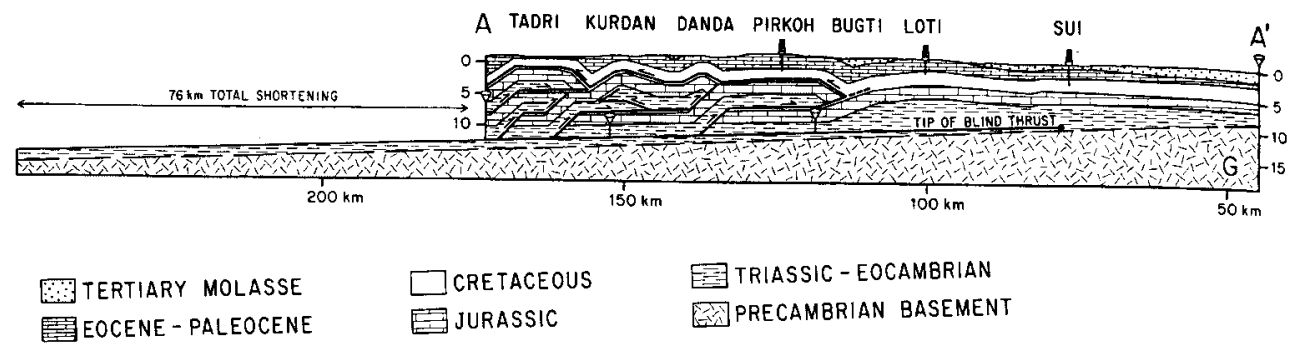

Fig. 2 - An antiformal stack over a basement slope of $2.5^{\circ}$ and after shortening of $37 \%$, in a balanced, NNW-SSE geological cross-section from the frontal Sulaiman fold belt of the Himalayan Mountain system in central Pakistan (after Jadoon et al. 1992).

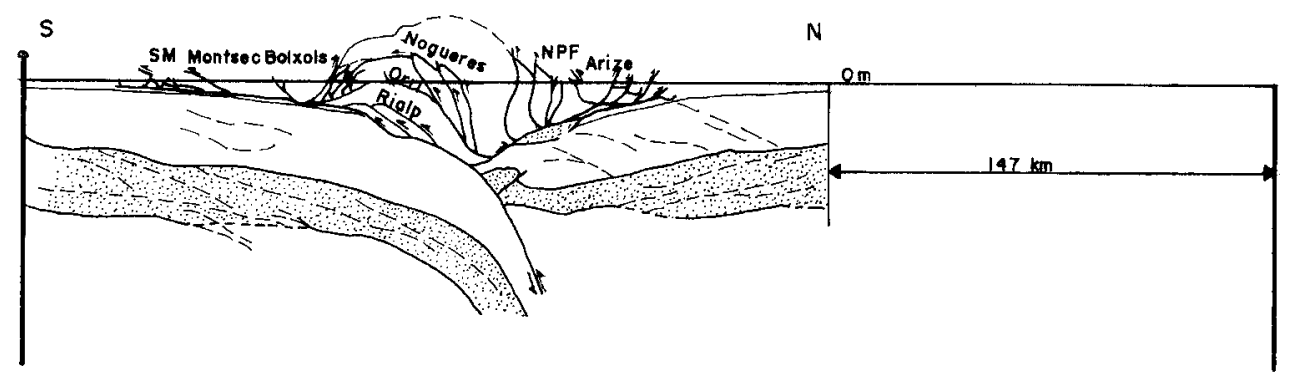

Fig. 3 - A basement-involved antiformal stack in a balanced cross-section of the middle of the Pyrenean continental collision belt, after 39\% shortening (Muñoz, 1992).

possible to their natural equivalents", it is necessary to produce geometric, kinematic and dynamic similarities. In an elastic body, length strain is proportional to stress and is time independent. Thus, the most important model ratios to simulate brittle deformation are those concerning stress (strength) and length. These ratios are related by the equation:

$$
\sigma_{R}=\delta \times \lambda\left(g_{m} / g_{o}=1\right),
$$

where

$$
\sigma_{R}=\sigma_{\text {model }} / \sigma_{\text {original }},
$$

the ratio between model and original strength,

$$
\delta=\delta_{\text {model }} / \delta_{\text {original }},
$$

the ratio between model and original densities,

$$
\lambda=\lambda_{\text {model }} / \lambda_{\text {original }},
$$

the model ratio of length, and

$g_{m} / g_{o}$, the ratio between model and original gravity acceleration.

The length ratio $\lambda=10^{-5}$, used in the present simulations $(1 \mathrm{~cm}$ in the model corresponds to 1 $\mathrm{km}$ in the natural prototype), requires a reduction of 100,000 times in the model strength. Thus, dry sand with strength near zero constitutes an ideal brittle analogue material. Since brittle deformation is time independent (Vendeville et al. 1987), the shortening in our experiments was produced with a constant displacement rate of $2 \mathrm{~cm} \mathrm{hr}^{-1}$.

In the present study, seven sets of experiments are described, five of them comprising two series of models (Table I). The difference between the two series relates to the material used for the backstop in the experimental boxes (Fig. 4). In one series, we have used a rigid, acrylic moving wall to simulate the 
TABLE I

Experimental details and figure numbers

\begin{tabular}{|c|c|c|c|c|c|c|c|c|}
\hline $\begin{array}{l}\text { Exp. } \\
\text { No. }\end{array}$ & $\begin{array}{c}\text { Thickness of } \\
\text { initial sand } \\
\text { layer }(\mathrm{cm})\end{array}$ & $\begin{array}{l}\text { Length of } \\
\text { initial sand } \\
\text { layer }(\mathrm{cm})\end{array}$ & $\begin{array}{l}\text { Type of } \\
\text { backstop }\end{array}$ & $\begin{array}{l}\text { Type of } \\
\text { "obstacle" }\end{array}$ & $\begin{array}{c}\text { Geometry of } \\
\text { basal } \\
\text { detachment }\end{array}$ & $\begin{array}{c}\text { Detachment } \\
\text { material }\end{array}$ & $\begin{array}{c}\text { Total } \\
\text { shortening } \\
(\%)\end{array}$ & $\begin{array}{l}\text { Figure } \\
\text { numbers }\end{array}$ \\
\hline M1-a & 3.0 & 30.0 & rigid wall & $\begin{array}{l}\text { high* } \\
\text { wooden block }\end{array}$ & horizontal & plastic sheet & 77 & 7 \\
\hline M1-b & 3.0 & 30.0 & sand pack & $\begin{array}{l}\text { high* } \\
\text { wooden block }\end{array}$ & horizontal & plastic sheet & 68 & 8 \\
\hline M2-a & 3.0 & 30.0 & rigid wall & $\begin{array}{l}\text { small* } \\
\text { wooden block }\end{array}$ & horizontal & plastic sheet & 80 & 9 \\
\hline M2-b & 3.0 & 30.0 & sand pack & $\begin{array}{l}\text { small* } \\
\text { wooden block }\end{array}$ & horizontal & plastic sheet & 68 & 10 \\
\hline M3-a & 0.9 & 20.0 & rigid wall & $\begin{array}{l}\text { fixed, } \\
\text { vertical end-wall }\end{array}$ & horizontal & plastic sheet & 70 & 11 \\
\hline M3-b & 0.9 & 10.0 & sand pack & $\begin{array}{l}\text { fixed, } \\
\text { vertical end-wall }\end{array}$ & horizontal & plastic sheet & 33 & 12 \\
\hline M4-a & 3.0 & 28.0 & rigid wall & $\begin{array}{l}\text { fixed, } \\
\text { vertical end-wall }\end{array}$ & slightly tilted $\left(5^{\circ}\right)$ & plastic sheet & 50 & - \\
\hline M4-b & 3.0 & 28.0 & sand pack & $\begin{array}{l}\text { fixed, } \\
\text { vertical end-wall }\end{array}$ & slightly tilted $\left(5^{\circ}\right)$ & plastic sheet & 50 & 13 \\
\hline M5-a & $\begin{array}{l}\text { thickness decreases } \\
\text { from } 3.0 \text { to } 1.0\end{array}$ & 32.0 & rigid wall & $\begin{array}{l}\text { fixed, } \\
\text { vertical end-wall }\end{array}$ & $\begin{array}{l}\text { inclined wooden } \\
\text { wedge }\end{array}$ & plastic sheet & 56 & 14 \\
\hline M5-b & $\begin{array}{l}\text { thickness decreases } \\
\text { from } 3.0 \text { to } 1.0\end{array}$ & 32.0 & sand pack & $\begin{array}{l}\text { fixed, } \\
\text { vertical end-wall }\end{array}$ & $\begin{array}{l}\text { inclined wooden } \\
\text { wedge }\end{array}$ & plastic sheet & 53 & 15 \\
\hline M6 & 3.0 & 40.0 & rigid wall & $\begin{array}{l}\text { fixed, } \\
\text { vertical end-wall }\end{array}$ & horizontal & sand paper & 45 & 16 \\
\hline M7 & $\begin{array}{c}\text { thickness decreases } \\
\text { from } 3.0 \text { to } 1.0\end{array}$ & 32.0 & rigid wall & $\begin{array}{l}\text { fixed, } \\
\text { vertical end-wall }\end{array}$ & $\begin{array}{l}\text { inclined wooden } \\
\text { wedge }\end{array}$ & sand paper & 56 & 17 \\
\hline
\end{tabular}

* wooden block is much higher than the initial sand layer

${ }^{* *}$ wooden block and initial sand layer have the same heights.

backstop of the deformation front (the "bulldozer" behind an accretionary wedge). As this material has a disproportionately large strength compared to the mechanical properties of the sand, we repeated some of the models using a deformable backstop. Thus, all series "a" models were deformed by a vertical rigid wall moving towards the foreland. In series "b" experiments, this moving wall was replaced by a sand pack, with mechanical properties similar to the rest of the model. All series "b" experiments still required a rigid moving wall connected to the motor, but this wall was located $16 \mathrm{~cm}$ behind the front of the sand pack (Fig. 4). The results show that a $16 \mathrm{~cm}$-long deformable sand pack is sufficient to prevent any interference by the rigid wall with the geometry of the thrust wedges.

All models were deformed in a rectangular (60 $\mathrm{cm} \times 20 \mathrm{~cm} \times 15 \mathrm{~cm}$ ), glass-sided, acrylic box that permitted the continuous observation of deformation. The models were serially photographed through the transparent sided wall. At the end of each experiment, the models were dissected and different internal sections were photographed. Each model presented in this paper was repeated at least twice with similar results.

The friction between the sand and the glass sides during horizontal shortening could not be avoided. It obstructs the forward displacement of the sand layer causing minor deformation at the side walls than in the center (Fig. 5). In the central cross section (Fig. 5C), the higher deformation resulted in a smaller distance between the branch line of the contractional fault system and the base of the obstacle than along the side wall (Fig. 5A), as well as a higher number of thrust planes. Another effect of the friction at the sidewall is that the trace of the thrust planes are expressed as wider shear zones. This friction also induces slightly different deformation patterns along the two side walls (Fig. 6). The geometric differences between the two side walls 


\section{SERIES "a" MODEL}

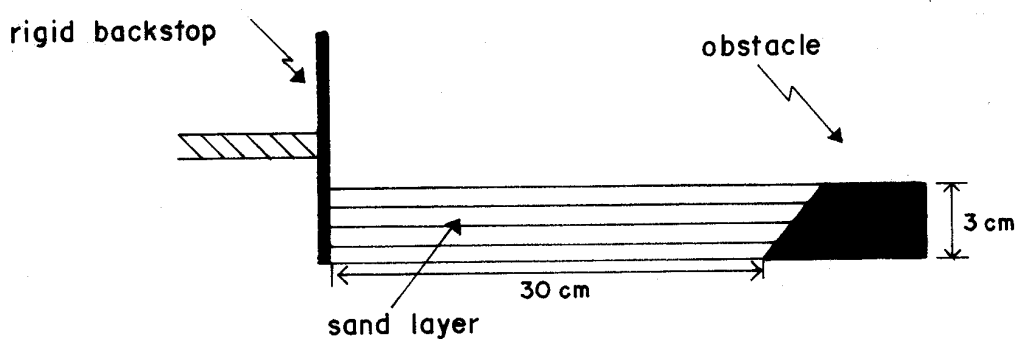

SERIES " $b$ " MODEL

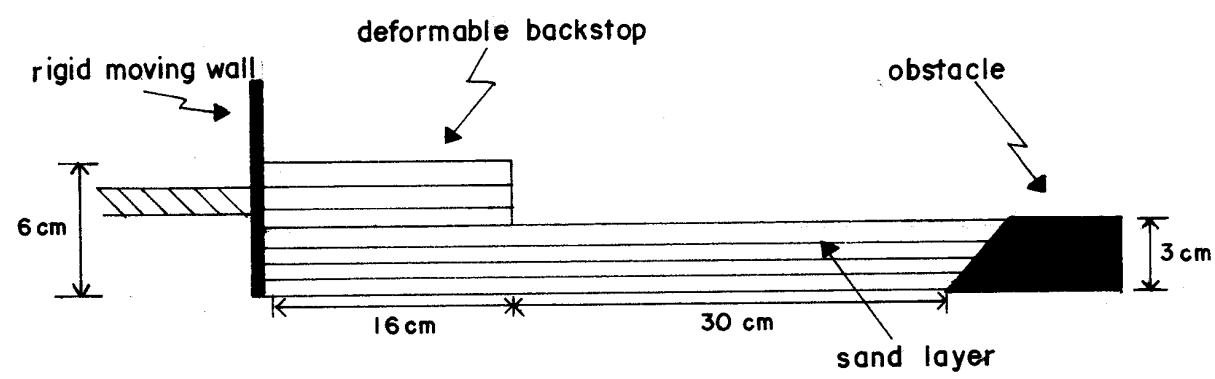

Fig. 4 - Sketches of the experimental boxes (models M2), illustrating the boundary conditions of series "a" and series "b" experiments.

are insignificant, however, and are assumed to be a result of minor irregularities in the sandbox and/or from manual handling of the analogue material. The drawings shown in Figures 7 to 17 were made from photographs taken during each model run, always on the same side wall.

All models were set up with a rigid obstacle in the foreland. The role of the obstacle was to block the evolution of a forward-breaking thrust sequence. In experiments M1 and M2, we introduced steeply dipping wooden blocks of different heights as obstacles. In experiments M3 to M7, the fixed, vertical end-wall of the sandbox serves this function. The aim of experiments M1 to M3 was to investigate the geometry of contractional systems when the progressive movement of the deformational front was completely impeded (set M1 and M3) or only partially, since displacement over the obstacle was possible (set M2). The disproportionate height of the obstacle in M1 and M3 has no analog in nature, and was set up only to achieve better understanding the role of an obstacle in the antiformal stack evolution. Model M3 is similar to model M1 in that displacement of the deformation front is completely obstructed, but was set up to examine the effect of different thicknesses on the antiformal stack evolution.

In models M4-M7, additional factors were analyzed. In models M4 and M5, we investigated the antiformal stack formation over a slightly dipping basal detachment. Model M4 was performed similarly to M2-b but, prior to compression, the experimental box was tilted $5^{\circ}$ towards the hinterland. Model M5 was built above a wooden wedge tilted $5^{\circ}$ towards the hinterland. The sand layers were deposited horizontally.

In experiments M1-M5, the basal plate was covered with a plastic sheet to simulate a detachment with a low friction coefficient ( $\mu=0.37$; Huiqi et al. 1992). Models M6 and M7 investigated the 


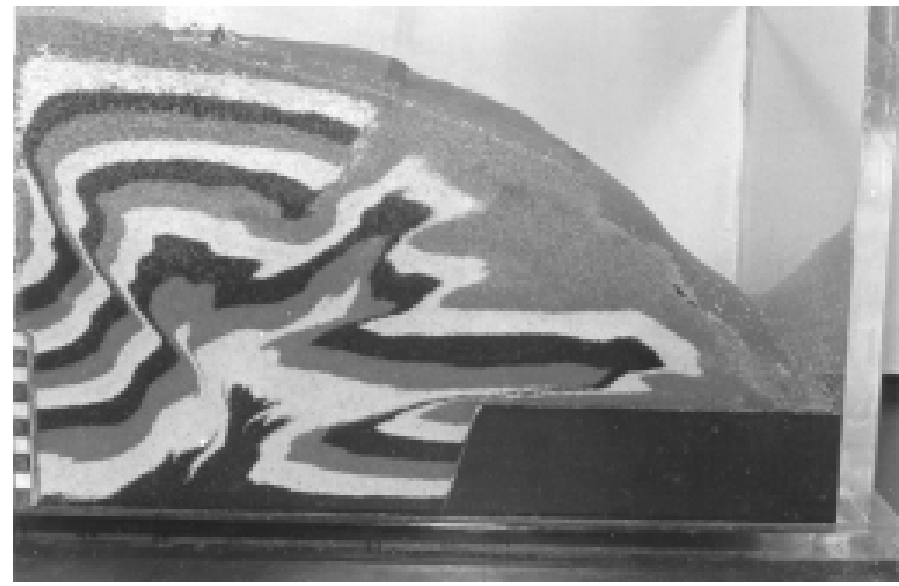

(A)

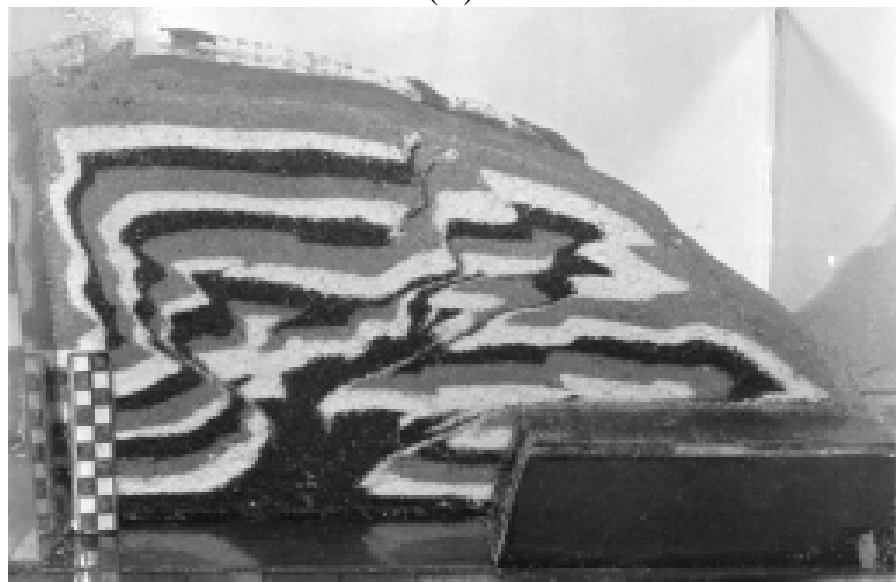

(B)

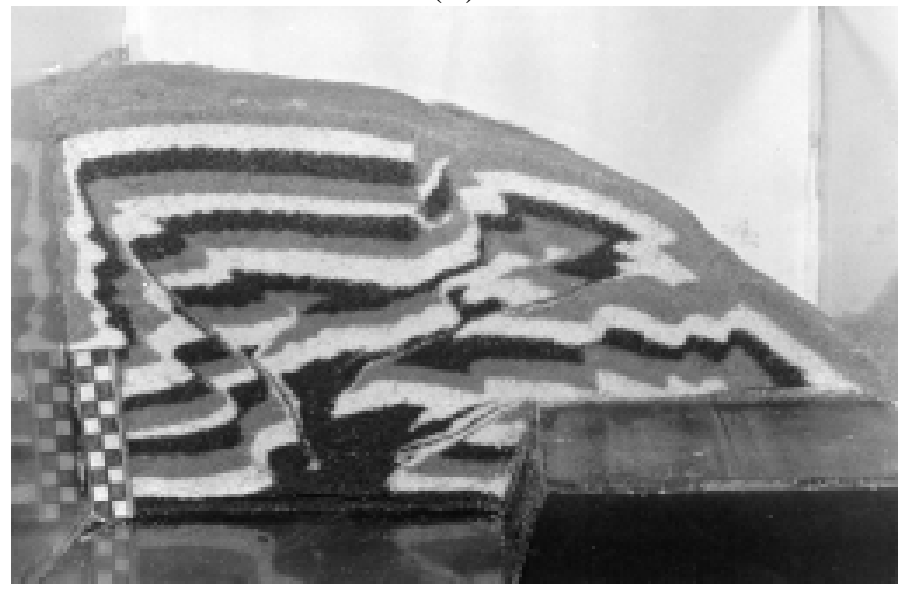

(C)

Fig. 5 - Photographs of serial cross sections of model M2-b, at the final stage of $68 \%$ shortening, showing an antiformal stack under decreasing influence of side wall friction. A - sideview through the model wall; B - section at $5 \mathrm{~cm}$ from the side wall; $\mathrm{C}$ - central section (at $10 \mathrm{~cm}$ from both side walls). Scale bar is $5 \mathrm{~cm}$. 


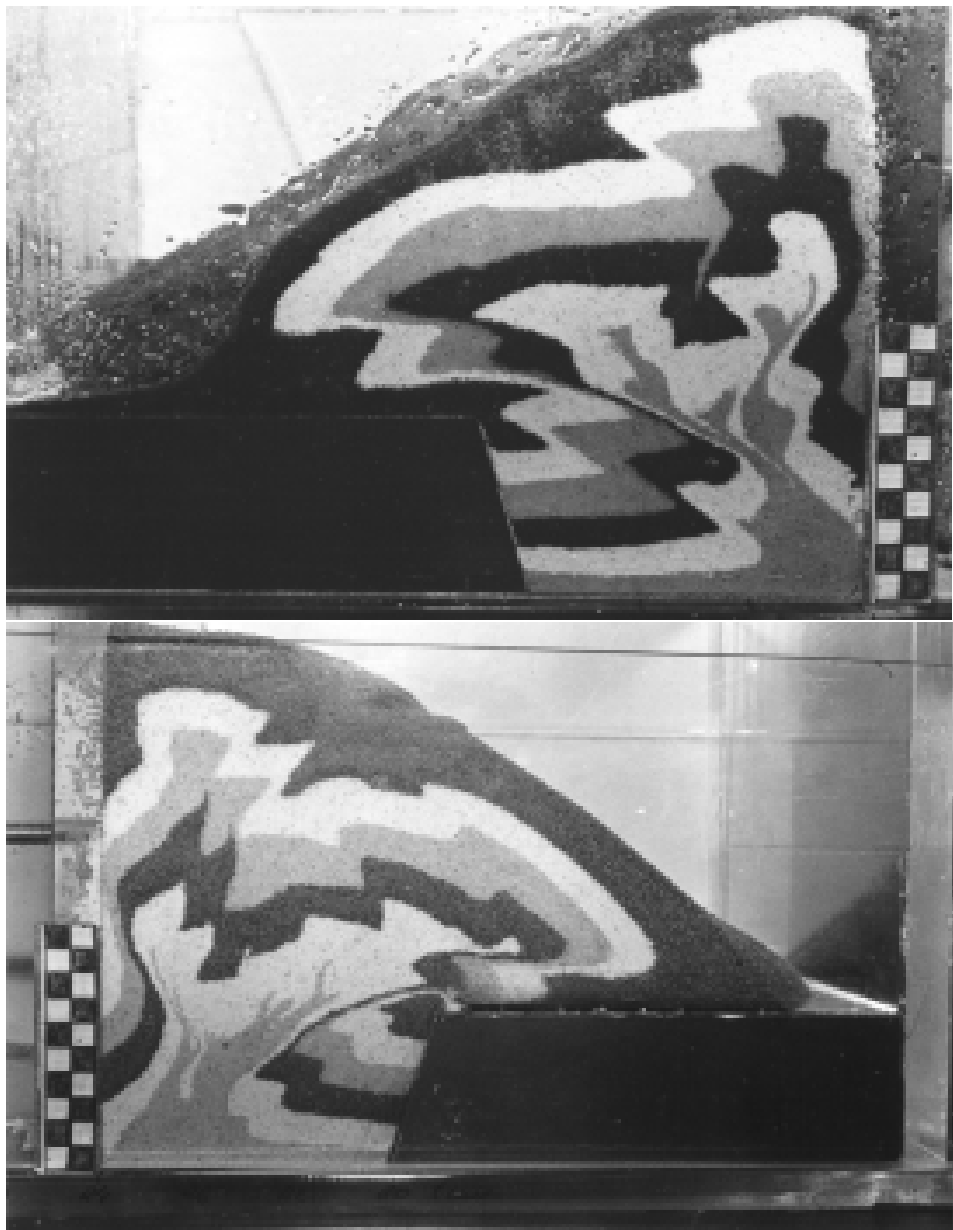

Fig. 6 - Two opposite side wall sections of the same experiment (model M2-a), after $80 \%$ shortening, revealing slightly different geometries in the antiformal stack (see text). Scale bar is $5 \mathrm{~cm}$.

effect of an increase in the basal friction. The base of the experimental box was covered with sand paper. Two situations were investigated: 1) a horizontal box (model M6), and 2) a box containing a $5^{\circ}$ inclined wooden wedge at its base (model M7).

\section{EXPERIMENTAL RESULTS}

\section{Models M1, M2 AND M3}

In experiments M1 and M2 (Figs. 7, 8, 9 and 10), two stages of deformation were recognized. The first stage consists of formation and growth of a true duplex in a forward-breaking sequence not influ- enced by the obstacle. The thrust system forms by displacement of the sand layer over the basal detachment, thickening and forethrusting of the deformation front, usually associated with a smaller backthrust. After faulting, the newly formed hanging wall is displaced over the thrust plane and the process is repeated. With the increasing mass of the thrust system, new faults in the foreland form farther from the older ones (Figs. 7c, 8b, 9c and 10c).

The second stage corresponds to the continued contraction of the thrust system with increasing influence of the obstacle. The displacement of the foreland is blocked, so that the shortening must be 


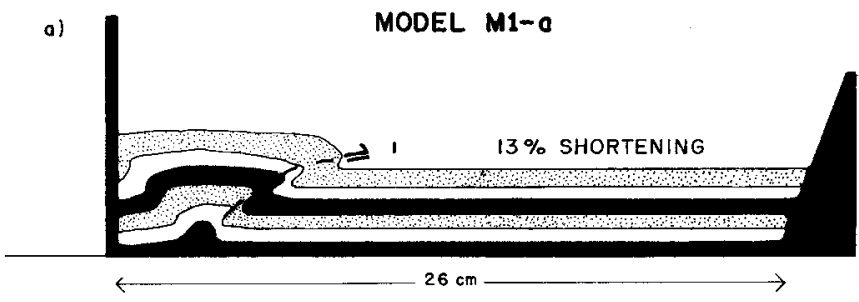

b)

$33 \%$ SHORTENING

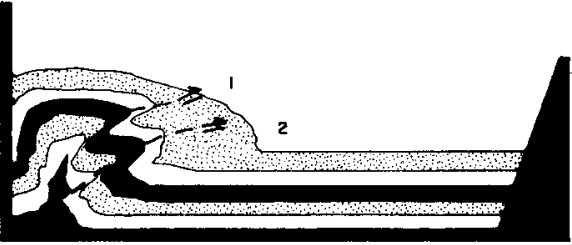

$20 \mathrm{~cm}$

c)

$53 \%$ SHORTENING
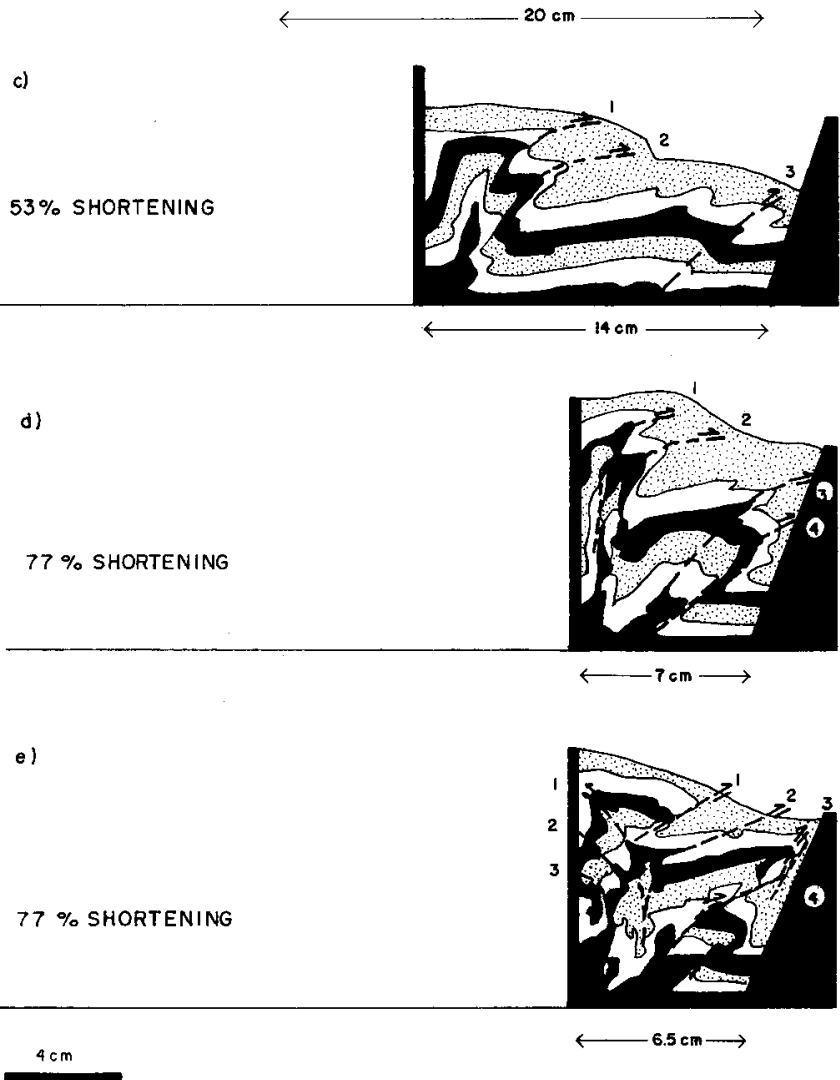

Fig. 7 - Successive stages of shortening in model M1-a (high obstacle and rigid backstop). The model evolves into an antiformal stack when the initial duplex system is further shortened. (a) to (d) are sideviews through the model wall; (e) is a section cut in the sand layers at the end of the experiment. (a) After $13 \%$ of shortening, the first thrust forms; (b) after $33 \%$, a second thrust appears and the system becomes a duplex; (c) after $53 \%$, a third thrust appears; (d) after $77 \%$ (final stage), the system becomes an antiformal stack; (e) final stage: cross section cut $5 \mathrm{~cm}$ away from the glass wall. Note the backthrusts near the rigid backstop. 


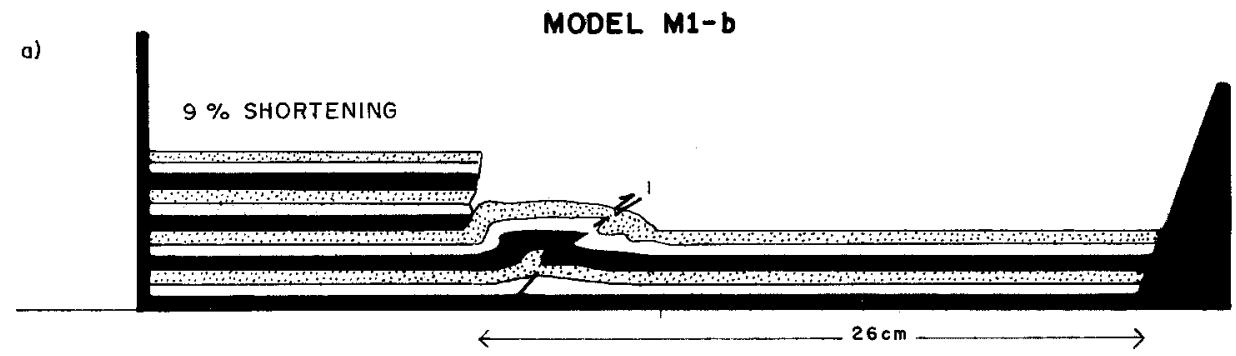

b)

$36 \%$ SHORTENING

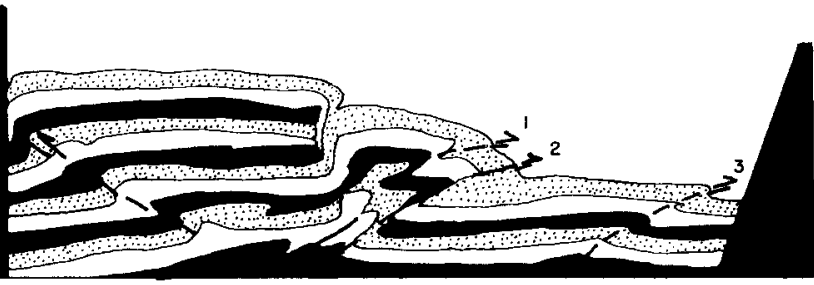

$\longleftarrow-14 \mathrm{~cm} \longrightarrow$

c)

$50 \%$ SHORTENING

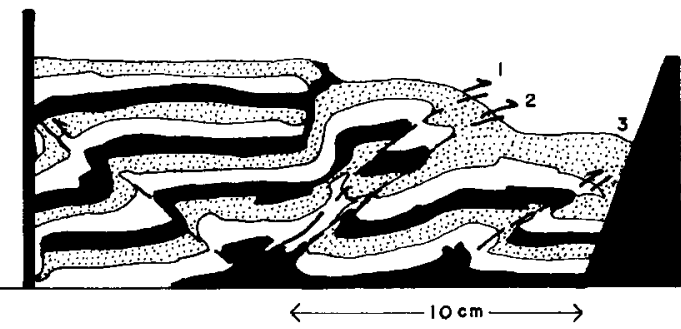

d)

$68 \%$ SHORTENING

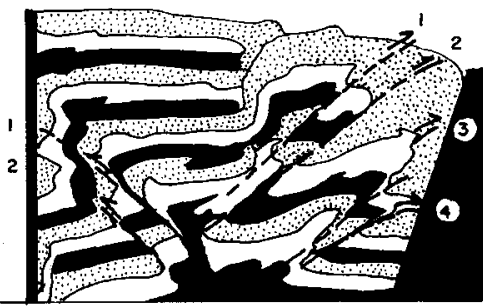

$\longleftarrow 6 \mathrm{~cm} \longrightarrow$

e)

$68 \%$ SHORTENING

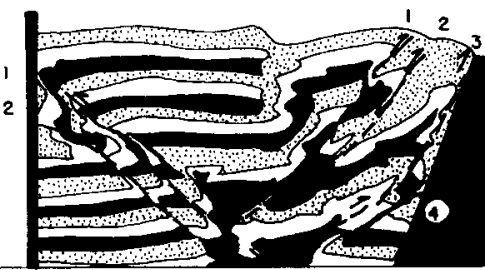

$\leftarrow 5 \mathrm{~cm} \longrightarrow$

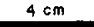

Fig. 8 - Sequential development of model M1-b (high obstacle and deformable backstop). The model illustrates the effect of a deformable backstop on the antiformal stack evolution of model M1-a after, (a) $9 \%$; (b) $36 \%$; (c) $50 \%$; (d) $68 \%$ shortening (sideview); and (e) after $68 \%$ shortening (section cut $5 \mathrm{~cm}$ from the glass wall). The difference between models M1-a and M1-b is the dip angle of the oldest thrusts (compare Figs. 8d, e and 7d, e). 

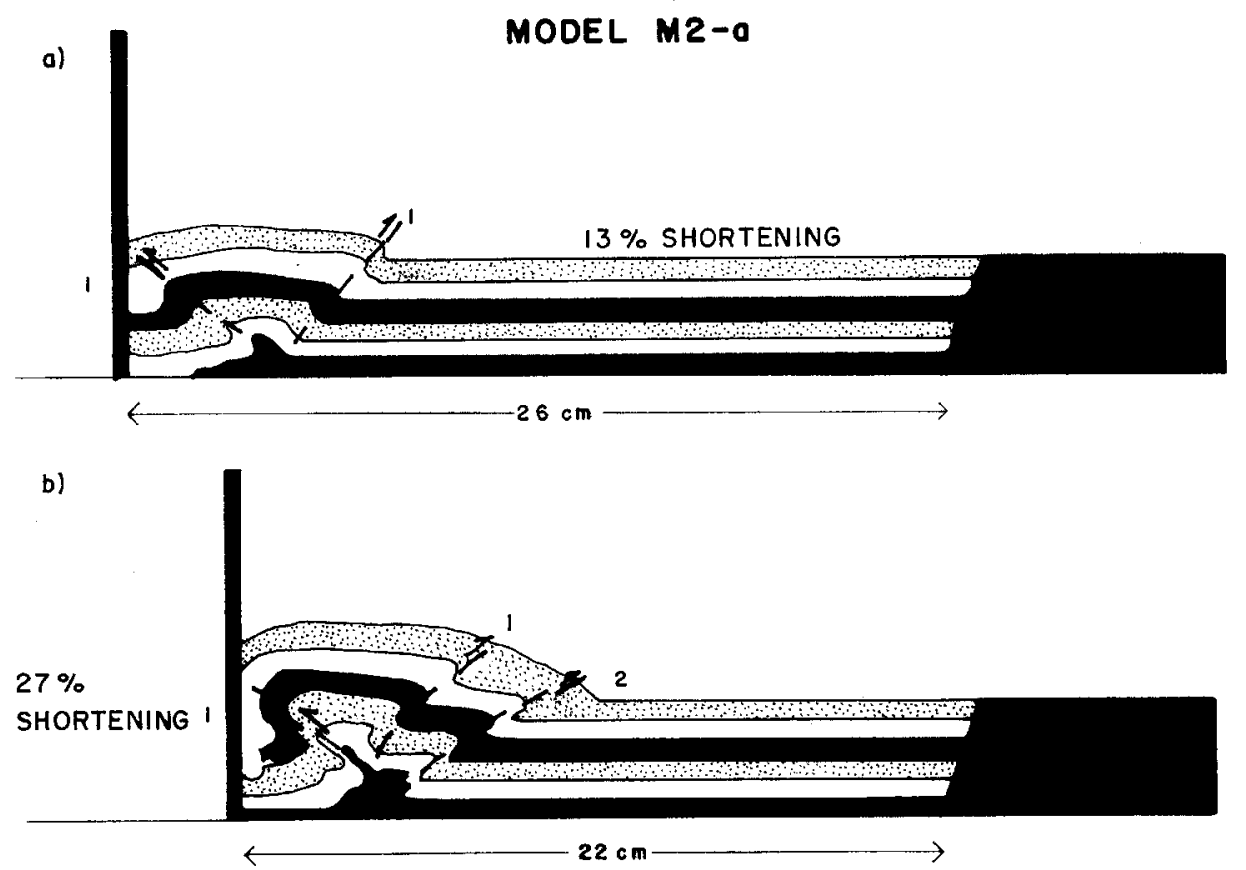

c)

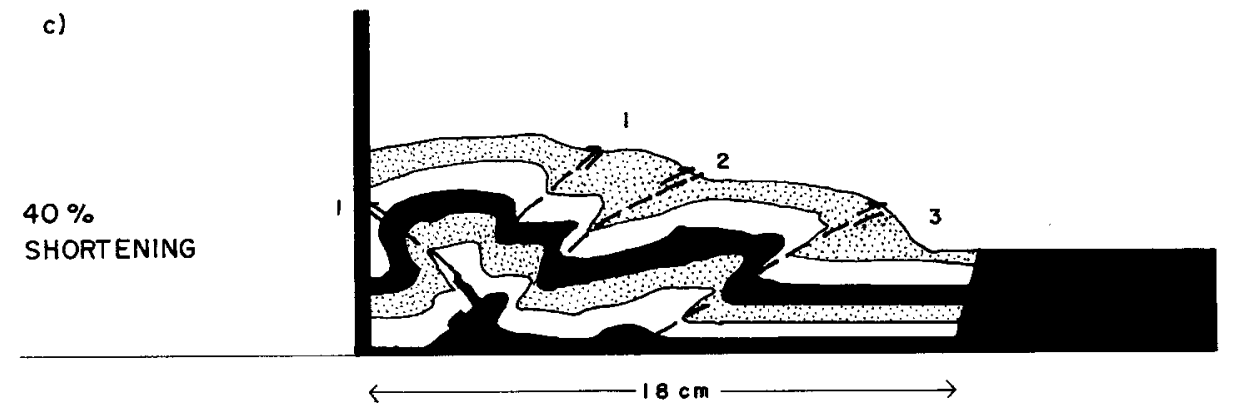

d)

$80 \%$ SHORTENING
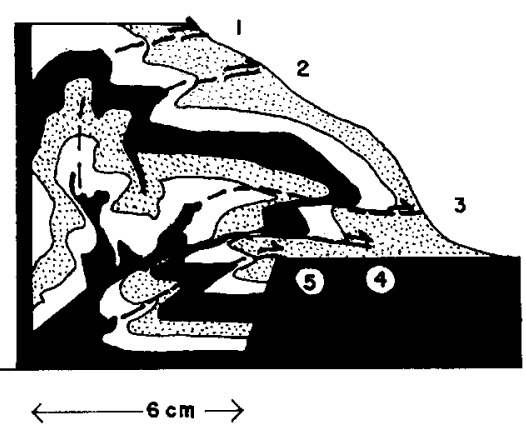

$4 \mathrm{~cm}$

Fig. 9 - Four successive stages of model M2-a (small obstacle and rigid backstop). The antiformal stack evolution of this model is very similar to model M1-a. After (a) $13 \%$; (b) $27 \%$; (c) $40 \%$; and (d) $80 \%$ shortening. Different structures, due to the obstacle height, appear only in (d). 
ब)

\section{MODEL MQ-b}

$8 \%$ SHORTENING
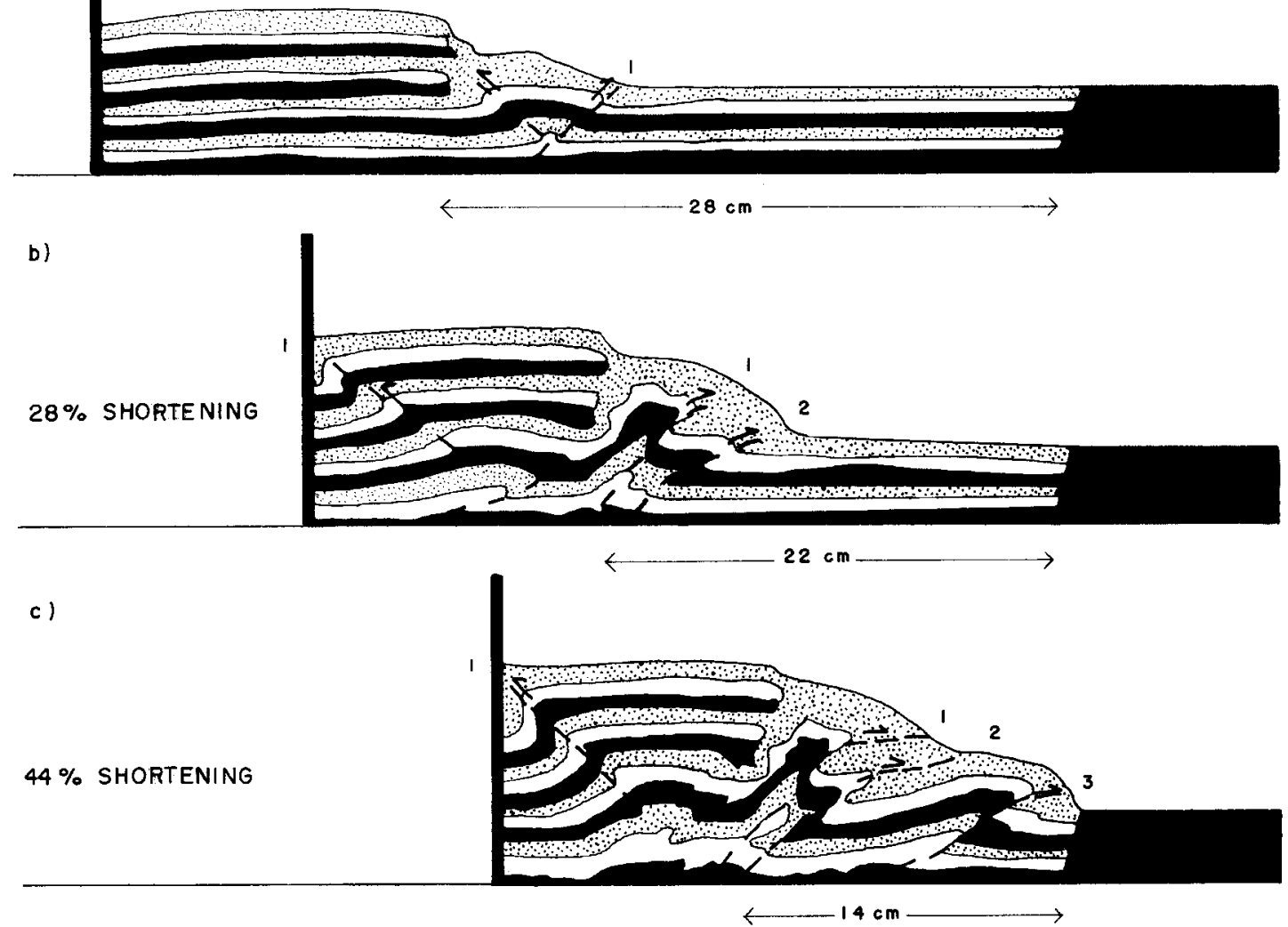

d)

$68 \%$ SHORTE NING

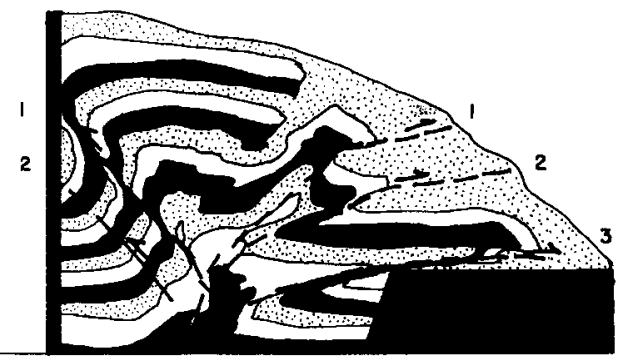

$\leftarrow 4 c m \rightarrow$

$4 \mathrm{~cm}$

Fig. 10 - Successive stages of model M2-b (small obstacle and deformable backstop). Model M2-b presents the same geometry as models M1-b and M2-a, after (a) 8\%; (b) 28\%; (c) 44\%; (d) 68\% shortening (sideview). Note the difference in the thrust geometry between Figs. 9d and 10d. Photographs in Figs. 5b, c also illustrate stage (d) of the present model in two more sections. 
accommodated by contraction of the hinterland. The hinterland contraction leads to convergence between branch lines until their total coincidence (Figs. 7e, 8d, 9d and 10d).

\section{Sequences M1 $-a$ AND M2 $-a$ : Rigid Backstop}

Models M1-a and M2-a, set up with a high and a low obstacle, respectively, and both with a rigid backstop, show the nucleation of an increasing number of forethrusts (and backthrusts), with initial dips around $30^{\circ}$ (Figs. 7a, b and 9a, b). The continuous generation of new thrusts induces passive back rotation of the older, nearly inactive faults (forethrusts 1 and 2), as described by Huiqi et al. (1992).

In model M1-a, after 53\% shortening, the tip of the youngest thrust (forethrust 3 ), which is slightly convex in map view, touches the obstacle, marking the end of the normal evolution of the duplex system (Fig. 7c). Shortening is then accommodated in the hinterland by strong movement along the older faults (1 and 2), where slip has never ceased completely. Strain along these faults is almost vertical and is accompanied by progressive decrease in the spacing between the thrust faults. Figure 7e shows that deformation has not ceased completely in the foreland, but continues at a lower rate. Thus, after $77 \%$ of shortening, the youngest thrust had a counter clockwise rotation of $10^{\circ}$ and serial sections revealed the presence of a steep displacement along the obstacle (thrust 3).

In model M2-a, the formation of new thrusts in the foreland is impeded by the obstacle after $40 \%$ shortening (Fig. 9c). In this model, the lower height of the obstacle has caused a smaller back rotation $\left(5^{\circ}\right)$ of the youngest forethrust 3 , and permitted a larger horizontal displacement as the deformation front can override the obstacle. The thrust system in the hinterland (forethrusts 1 and 2) has moved vertically and was then forced to override the younger faults (Fig. 9d).

In models M1-a and M2-a, a shortening greater than $4 \%$ produces a deformation partitioning between the foreland and the hinterland. In the hinter- land, both models undergo vertical strain and progressive convergence of branch lines. In contrast, deformation in the foreland occurs at a lower rate, the high obstacle causing a vertical strain and the small obstacle allowing a basal horizontal displacement. After a very large shortening (70-80\%), the branch lines become coincident and, according to the definition proposed by McClay (1992), a typical antiformal stack is formed. New forethrusts may form to accomodate further deformation in the foreland, between the branch line and the obstacle.

\section{Sequences M1 $-b$ and M2 $-b$ : Deformable BACKSTOP}

In models M1-b and M2-b, an antiformal stack was formed in a similar way as in experiments M1-a and M2-a, i.e. through deformation in the foreland followed by contraction of the hinterland and vertical strain (Figs. 8 and 10).

At the beginning of deformation of models M1b and M2-b, an ordinary duplex system develops, and a backthrust appears in the deformable backstop (Figs. 8a, b and 10a, b). The progressive deformation shown in figures $8(\mathrm{c}, \mathrm{d})$ and $10(\mathrm{c}, \mathrm{d})$ demonstrates that the deformable backstop impedes the strong back rotation of the oldest forethrusts (1 and 2), as occurred in the M1-a experiment and also in other previously published experiments (e.g. Mulugeta \& Koyi 1992; Huiqi et al. 1992). Forethrusts 1 and 2 undergo only a slight back rotation and when the high obstacle, in model M1-b, interrupts the normal evolution of the duplex, i.e. after 30\% shortening (Fig. 8b), the slip on forethrusts and backthrusts increases. The high resistance to sand layer displacement generates, after $50 \%$ contraction, a new forethrust (4) and backthrust (2), as well as the convergence between the trailing and leading branch lines (Figs. 8c and d). Forethrusts and backthrusts accommodated further contraction by strain in the vertical direction, producing a pop-up-like structure (Figs. 8d and e).

In model M2-b, the obstacle height is equal to that of the original sand layer, and offers a relatively 
low resistance in the foreland. This low resistance leads to fewer forethrusts after $68 \%$ shortening. The geometry of the M2-b antiformal stacks differs from that of model M1-b only by showing a higher basal horizontal displacement.

In models M1-b and M2-b, the deformable backstop accommodates part of the deformation through backthrusting. In addition, during the evolution of the antiformal stack, smaller back rotation of the older forethrusts and lower vertical strain occur in the hinterland than in models M1-a and M2-a. These models demonstrate that, to produce an antiformal stack, a deformable backstop requires less shortening than a rigid one (68\% in model M2-b vs. $80 \%$ in model M2-a). Finally, the series "b" experiments reveal that the deformable backstop causes less partitioning of deformation between foreland and hinterland in an antiformal stack.

\section{Sequence M3 $-a$ And M3 $-b$ : High Obstacle} AND THIN SAND LAYER

The main factor controlling the formation of the antiformal stacks in these experiments is the extremely low thickness of the initial sand layer $(0.9 \mathrm{~cm})$. The relationship between the sand layer thickness and the spacing between thrusts has been previously documented by Huiqi et al. (1992). Variations in sand column thickness cause different deformation rate due to the change in sand volume. The smaller the volume, the smaller is the minimum principal stress, $\sigma_{3}$, which is vertical in a compressional system. As a consequence, the differential stress $\left(\sigma_{1}-\sigma_{3}\right)$ applied to the sand pack increases more quickly with a smaller volume, causing a higher deformation rate, i.e. a larger number of faults form with a smaller fault spacing, for a given shortening.

Deformation of model M3-a, set up with a rigid backstop (Fig. 11), confirms that a thin sand column deforms along closely spaced thrusts. In addition, shortening promotes high slip on the thrusts and consequent thickening of the deformation front. The first two thrusts are immediately back rotated in order to accomodate progressive shortening (Figs. 11a, b). After $30 \%$ shortening (Fig. 11c), a new forethrust forms, further away, and the process repeats with thrust back rotation, vertical strain and convergence between branch lines (Figs. 11d-f). Exactly the same kinematic process occurs in model M3-b (Figs. 12b-d).

Model M3-b was carried out with a $3.0 \mathrm{~cm}$ thick deformable backstop, much thicker than the sand layer $(0.9 \mathrm{~cm})$. In the initial stage of shortening, the backstop strongly resisted deformation (Figs. 12ad), producing structures in the sand layer which are very similar to those of model M3-a (Fig. 11). With further shortening, the influence of the obstacle in the foreland impedes the displacement of the thrust wedge. The resistance of the obstacle exceeds the resistance of the sand backstop, and a backthrust forms (Fig. 12e). The important point in this model is that the large back rotation of the oldest forethrusts (1 and 2) may be attributed to the rigidity of the thick deformable backstop. The slightly different geometries between models M3-a and M3-b result from the higher vertical strain in the former, caused by its stiffer backstop.

The typical evolution of a duplex system, as in the initial stages of deformation in models $\mathrm{M} 1-\mathrm{a}$ and M2-a, does not occur in models M3. Instead, thrusting, back rotation and vertical strain begin at lower displacement and continuously produce an antiformal stack (Figs. 11 and 12).

Model M3-b (Figs. 12d and e) has produced the best simulation of an anticlinal stack, when compared to McClay's definition (Fig. 1). Thus, this experiment reveals that an obstacle in the foreland, a high deformation rate and low edge effect, due to the backstop, constitute the main boundary conditions for antiformal stack formation in sandboxes.

Models M4, M5, M6 and M7 (Antiformal Stack Modelling Under AdDitional Factors)

Models M4 were tilted $5^{\circ}$ forward after model construction, and include either a rigid backstop (M4-a) (not shown) or a sand-composed, deformable backstop (M4-b) (Fig. 13). These models deformed in 

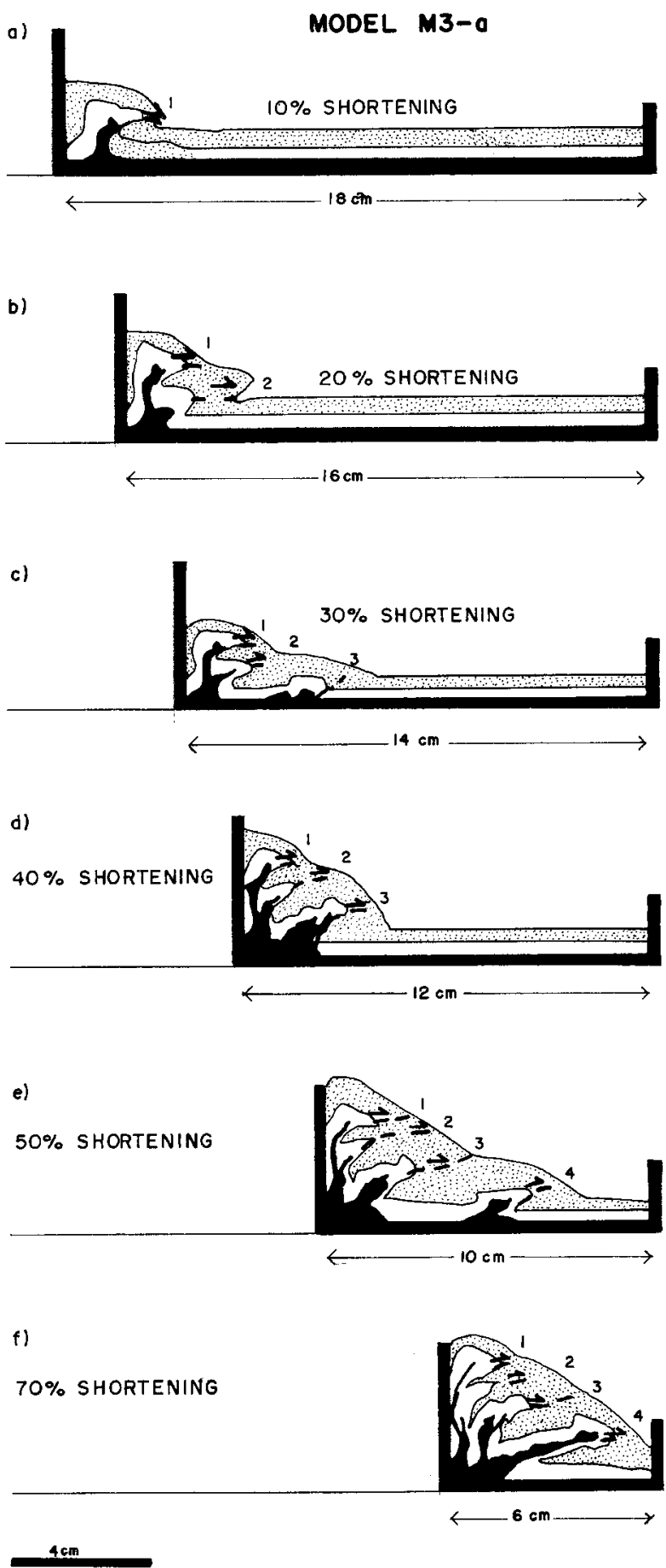

Fig. 11 - Six successive stages of model M3-a (high obstacle, initially thin sand layer and rigid backstop). This model shows strong vertical strain. After (a) $10 \%$; (b) $20 \%$; (c) $30 \%$; (d) $40 \%$; (e) $50 \%$; and (f) $70 \%$ shortening. 

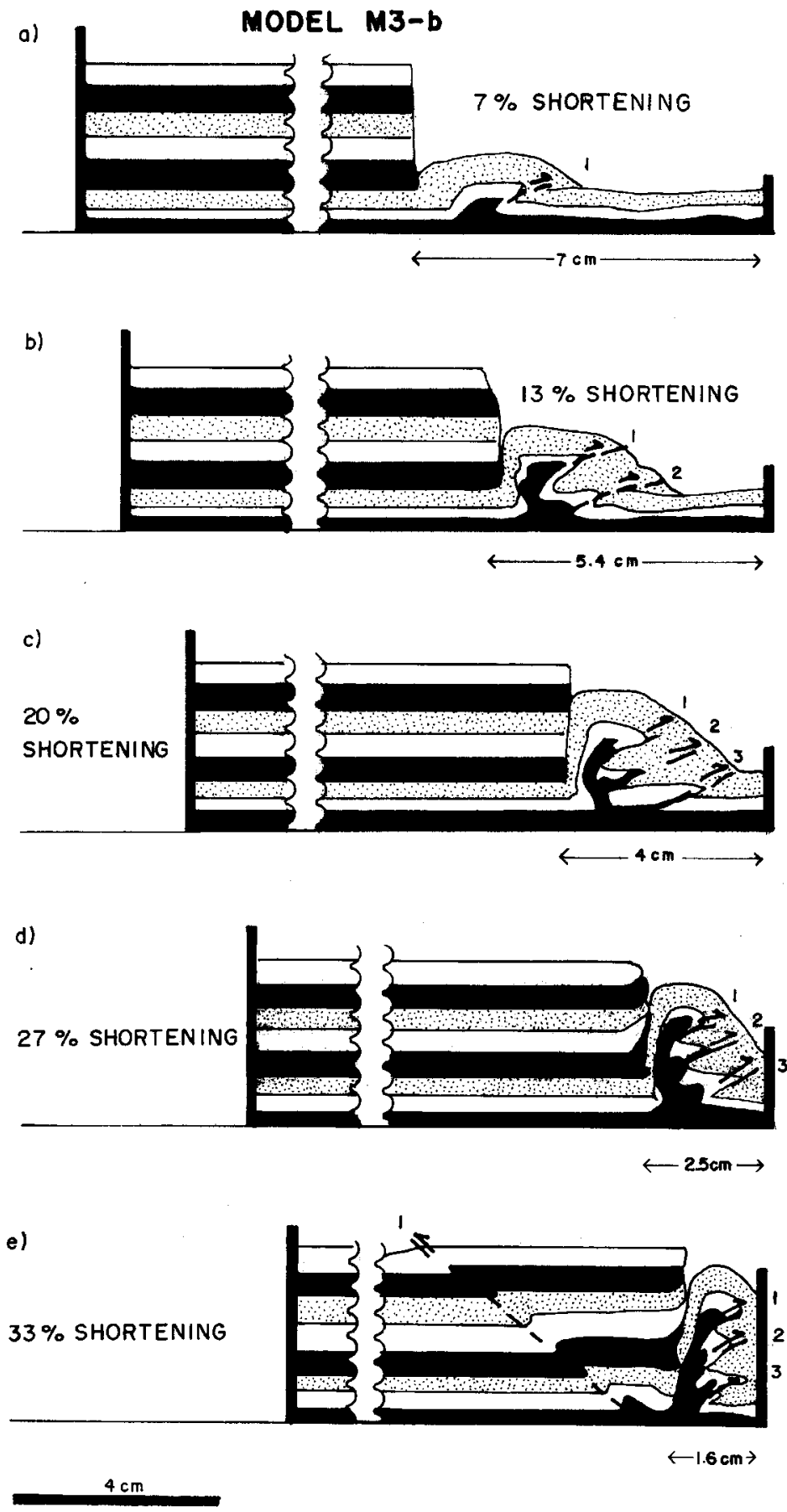

Fig. 12 - Five successive stages of model M3-b (high obstacle, initially thin and short sand layer and deformable backstop). The experiment, after (a) 7\%; (b) $13 \%$; (c) $20 \%$; (d) $27 \%$; and (e) $33 \%$ shortening. Note the same deformation pattern as in model M3-a. However, the shorter contractional domain and the deformable backstop produce a more homogeneous geometry in the antiformal stack. 
exactly the same way as the horizontal models M2-a and M2-b. In contrast, the results of models M5, M6 and M7 show some differences in the geometry of the antiformal stack.

Models M5 had a wedge shaped horizontal sand layer thinning toward the foreland above a hinterland dipping base. These models were also carried out using two types of backstop (Figs. 14 and 15). A different fault system was formed than those observed in previous models, probably due to the foreward decrease in the thickness of the sand layers above the dipping base. In the initial stages of deformation, the system can be classified as an independent ramp anticline thrust system (McClay, 1992) (Figs. 14b and 15b). With greater shortening, however, the displacement is blocked at the foreland and each ramp system undergoes back rotation. After 56 and 53\% shortening in models M5-a and M5$\mathrm{b}$, respectively, only the forethrusts closest to the obstacle (2, 3 and 4 (Fig. 14c) and 3, 4 and 5 (Fig. 15c)) become an antiformal stack with coincident branch lines. In contrast with models M1-b (Fig. 8), M2-b (Fig. 10) and M3-b (Fig. 12), the deformable backstop in model M5-b does not appear to have affected the fault geometry in front of it.

Experiments M6 (Fig. 16) and M7 (Fig. 17), set up with sandpaper to provide a high basal friction, show a strong increase in the critical wedge taper. In the horizontal box (model M6), the high basal friction inhibits the formation of a duplex system during the early stages of deformation. Shortening produces antiformal stacks only by thrusting, back rotation and vertical strain of the analogue material (Fig. 16). A similar evolution has been observed in models M3-a (Fig. 11) and M3-b (Fig. 12). In these models, however, the increase in the wedge taper was a consequence of both the low thickness and the relatively short length of the sand layers.

The effect of basal friction has been discussed by Huiqi et al. (1992), who demonstrated that an increase in basal friction produces an increase in both the critical taper and the length of each thrust plane. Models M6 (Fig. 16) and M7 (Fig. 17) differ in the length of the thrust slices and in the displacement of the foreland. The longer thrust slices and larger fault slips in model M7 (Fig. 17) are interpreted as a consequence of the easier foreland displacement due to the decreasing thickness of the sand layer over the tilted base.

\section{DISCUSSION}

The experiments described above demonstrate that antiformal stacks result from the interruption or complete impediment of the regular forward development of a foreland-vergent duplex system. Physical models show intense deformation in the hinterland due to the obstruction of displacement at the deformation front. However, some important parameters acting on deformation of natural rocks, such a pore-fluid pressure and the plastic behavior of rocks in the deeper parts of crystalline thrust sheets, could not be considered in the experiments.

The evolution of thrust systems in the external parts of mountain belts are relatively well studied in their theoretical aspects (e.g. Davis et al. 1983; Dahlen 1990; Suppe et al. 1992; Mosar \& Suppe 1992). Analogue modelling of thrust systems in accretionary wedges and fold-and-thrust belts are in broad agreement with the critical-taper Coulomb wedge model (Huiqi et al. 1992).

In the internal parts of orogens, thrusting transports slices of basement rock and produces complex thrust systems. Hatcher \& Hooper (1992) reviewed the existing mechanical models of thrust faulting in both external and internal parts of orogens and discussed their features. They proposed a rheological relationship between the three end-members of thrust sheet types: accretionary wedge, foreland fold-thrust belts and crystalline thrust sheets (type $\mathrm{C}$ and type F), and argued that one type of thrust sheet may evolve into another during progressive deformation.

Even though some aspects remain debated, the mechanics of the upper crystalline thrust sheets (type C) appear to be comparable to those of thin-skinned thrusts (Elliott \& Johnson 1980). However, the crys- 


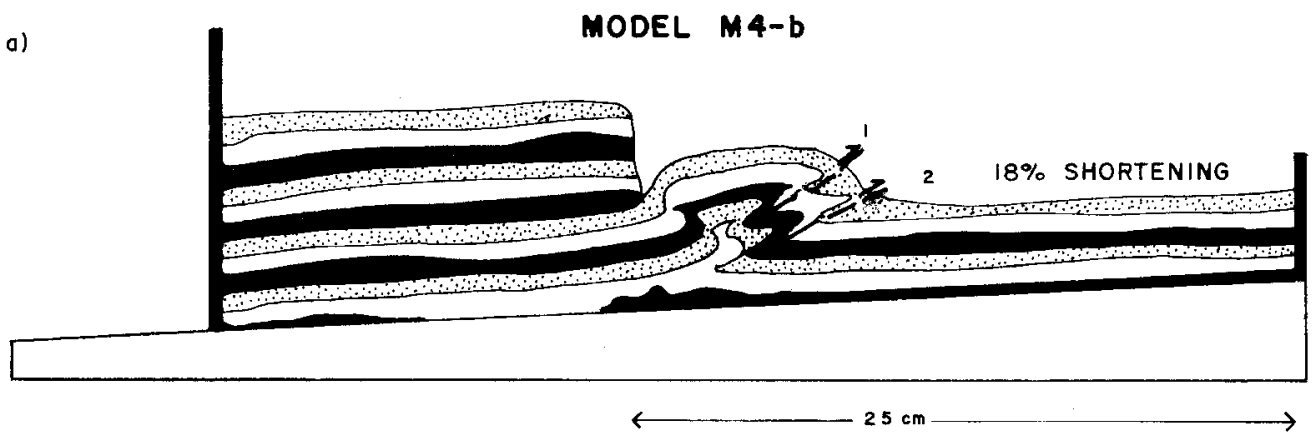

b)

$36 \%$ SHORTENING

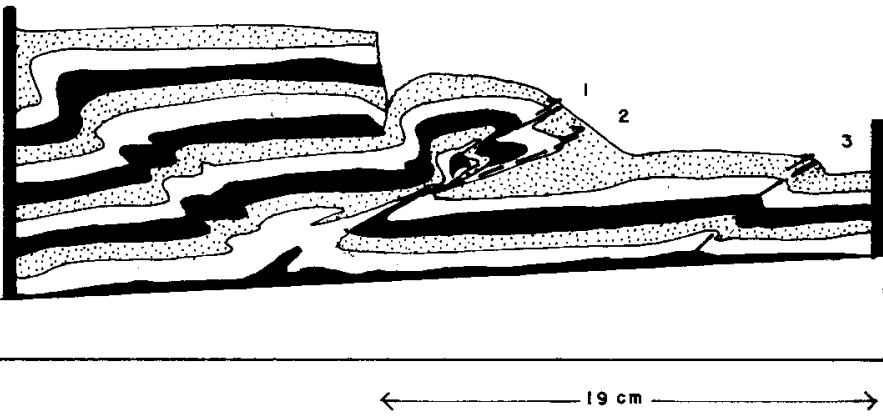

c)

$50 \%$ SHORTENING
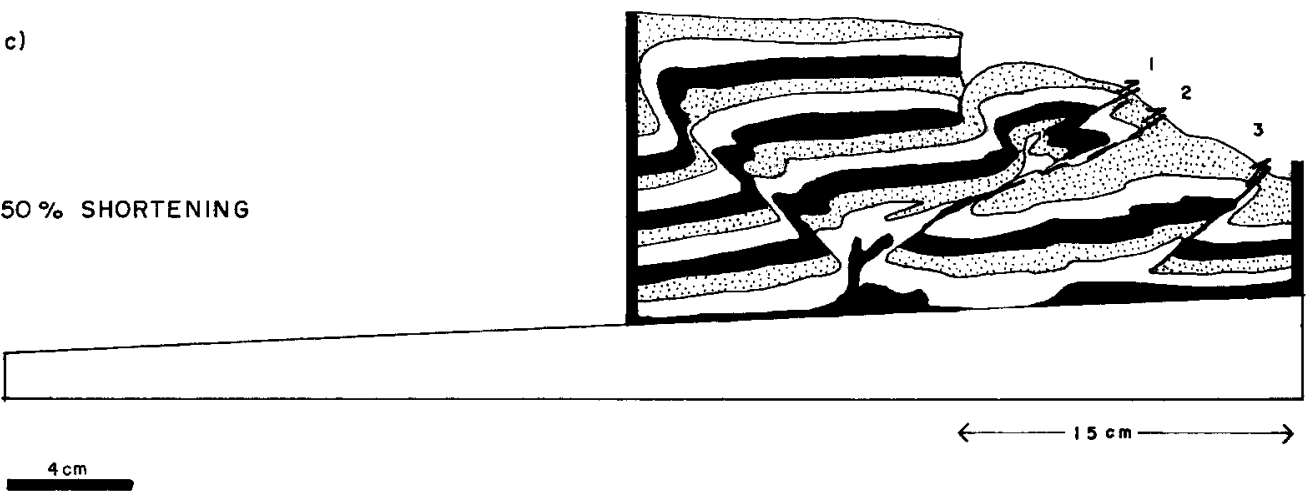

Fig. 13 - Model M4-b in three successive stages (the same boundary conditions as in model M2-b with additional $5^{\circ}$ tilt towards the hinterland). After (a) 18\%; (b) 36\%; and 50\% shortening. Deformation is the same as in model M2-b.

talline thrust sheets are characterized by a greater inherent strength because of their composition and the lack of initial horizontal layering which characterizes thin-skinned settings. In accretionary wedge and foreland fold-thrust belts, however, horizontal layering is assumed to provide zones of weakness along which detachments may occur. Since these zones of weakness are not taken into account in the analogue models presented here, we may assume that the basic principles of physical modelling remain valid for the internal parts of orogens.

Antiformal stack systems are thrust systems which are rare in the external parts of mountain chains but common in the internal parts, mainly in 

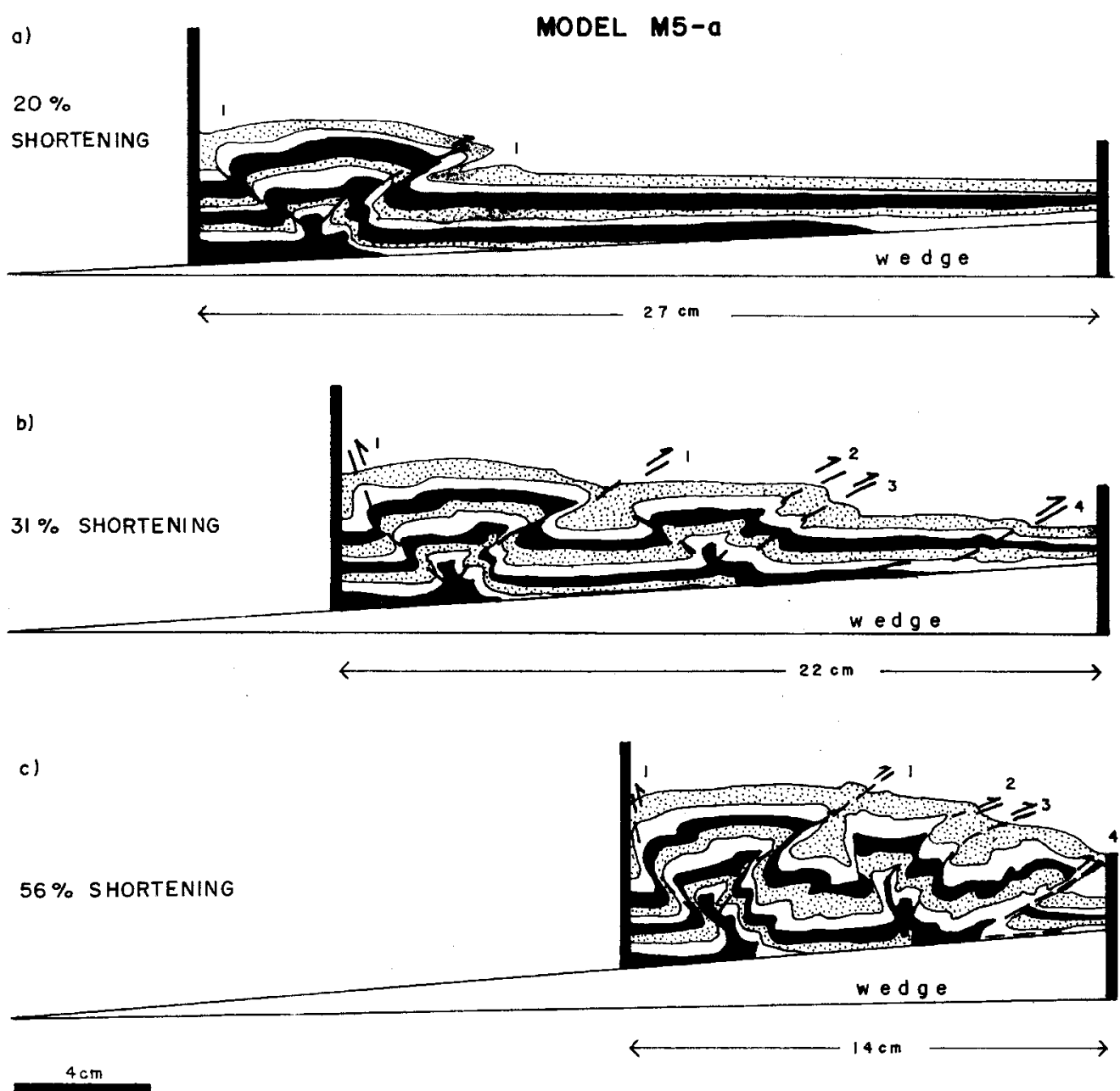

Fig. 14 - Model M5-a with a $5^{\circ}$ inclined basal wedge in the foreland and a rigid backstop. (a) After $20 \%$ shortening; (b) after $31 \%$ shortening, a duplex system consisting of independent ramp anticlines is formed; and (c) after 56\% shortening, the youngest independent ramp anticline has become an antiformal stack.

continent-continent or arc-continent collision zones. In sand models, antiformal stacks only form when the advancement of the foreland is totally (models M1, Figs. 7 and 8; and models M3, Figs. 11 and 12) or partially blocked (models M2, Figs. 9 and 10). As a consequence, the older thrust sheets of the hinterland pile up above the younger ones. In collision zones, the subducted plate acts as an obstacke, the key boundary condition to form antiformal stack systems (models M1, M2 and M3). In external oro- genic zones, obstacles may exist but only in special structural settings. They occur where pre-existing faults produce basement highs during tectonic inversion, or where the dip of the detachment impedes progressive displacement (see models M4-b, Fig. 13; M5, Figs. 14 and 15; and M7, Fig. 17), as shown by Jadoon et al. (1992) in the Sulaiman fold belt in the western margin of the Indian plate.

Boyer (1992) discussed why the typical model for duplex system evolution in a forward-breaking 


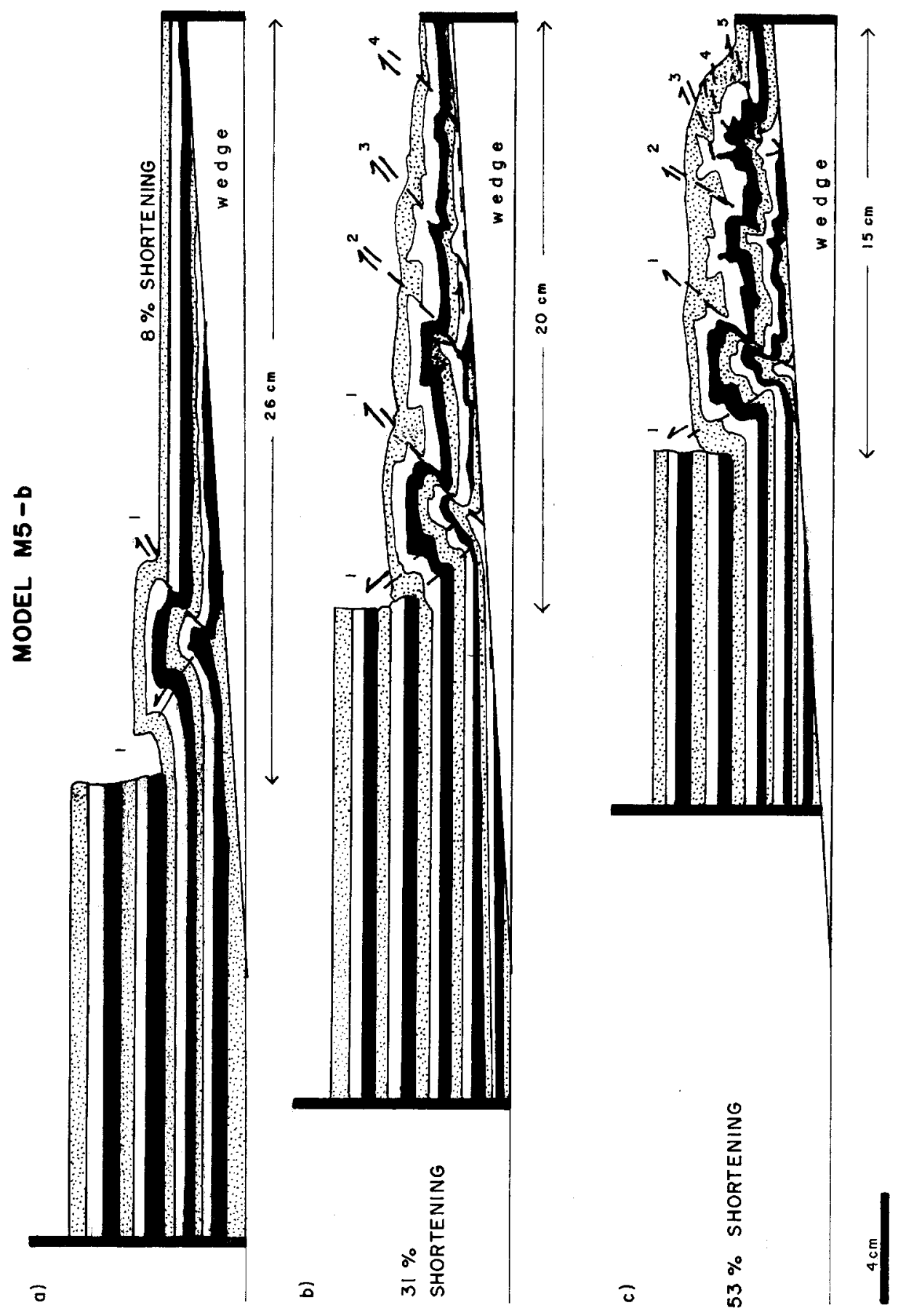

Fig. 15 - Model M5-b with a $5^{\circ}$ inclined wooden wedge in the foreland and deformable backstop. (a) After $8 \%$ shortening; (b) after 31\% shortening, a thrust system similar to model M5-a formed. (b) After 53\% shortening, an antiformal stack develops in the foreland. 
MODEL MG

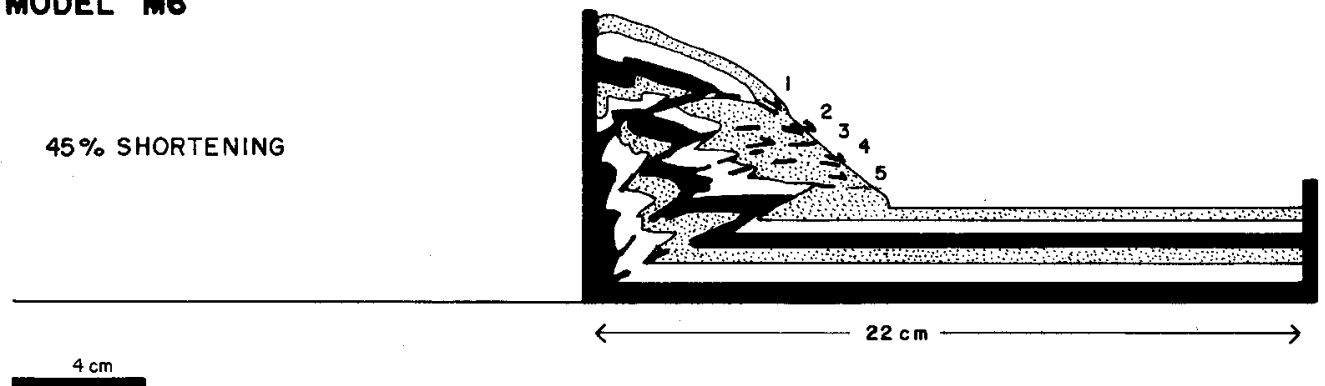

Fig. 16 - Model M6 with a high basal friction and a horizontal base, after $45 \%$ shortening. The high basal friction inhibits the displacement of the foreland, producing a compressional system characterized by strong vertical strain. Note the geometry of the bottom black layer.

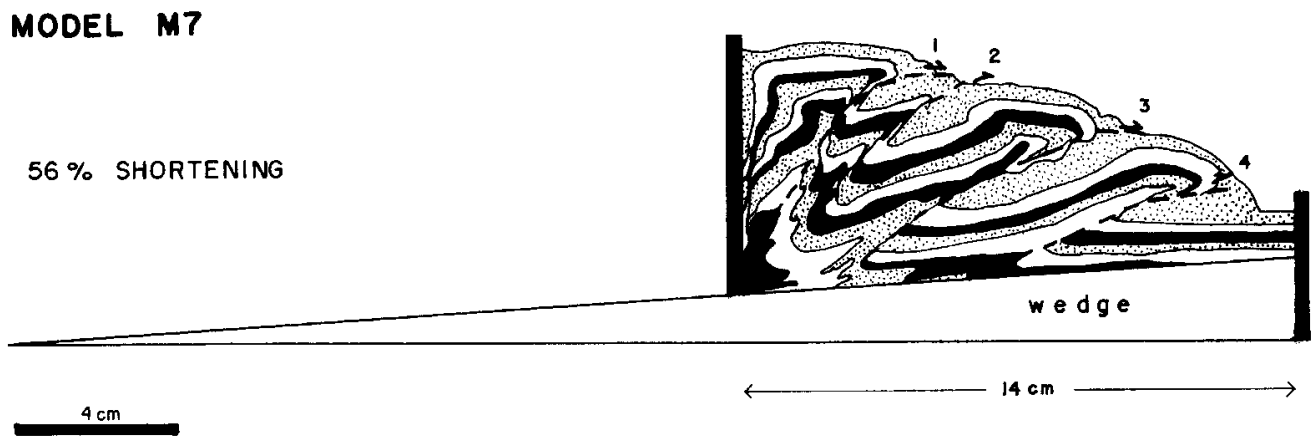

Fig. 17 - Model M7 with a high basal friction and a $5^{\circ}$ inclined basal wedge in the foreland, after $56 \%$ shortening. This model shows a similar antiformal stack as in model M1.

sequence (Boyer 1978, Boyer \& Elliott 1982) fails to explain some thrust system geometries. The experiments in his study also suggest that this model for duplex evolution is not always appropriate. My experimental results demonstrate that the presence of an obstacle causes thrust systems to evolve from an initial forward-breaking sequence in the foreland, to continued deformation in the hinterland. The last stages of shortening in models M1 and M2 (Figs. $7 \mathrm{c}, \mathrm{d} ; 8 \mathrm{c}, \mathrm{d} ; 9 \mathrm{c}, \mathrm{d}$ and 10c, d) characterize well this evolution. When the youngest fault reaches the obstacle in the foreland, synchronous thrusting occurs on this fault and along the reactivated oldest thrusts, in the hinterland.

Thrust systems also evolve from an alternat- ing deformation between foreland and hinterland as seen in models M3 and M6 (Figs. 11, 12 and 16), where each thrust was immediately followed by vertical strain in the hinterland. A comparison between models M1/M2 and model M3 demonstrates that an initially thick sand layer promotes propagation of deformation into the foreland before deformation resumes in the hinterland.

Conversely, a thin sand layer induces an alternating deformation between foreland and hinterland. A high deformation rate in the thin sand layer makes the forethrust back rotation mechanically easier in the relative low strength hinterland, preventing nucleation of a new forethrust in the foreland (higher strength). 
Model M6 (Fig. 16) shows that a high basal friction induces formation of antiformal stacks similar to those shown in models M3-a (Fig. 11f) and M3-b (Fig. 12d), which were carried out with a low basal friction and an obstacle in the foreland Therefore, these experimental results suggest that the impediment to foreland displacement does not need to be an obstacle at the deformational front, but simply a high friction basal detachment.

While the geometry and deformation mechanisms of model M6 are in good agreement with those of model M3, the geometry and deformation of model M7 (Fig. 17) (also set up with a high basal friction) is somewhat similar to experiments M1 (Fig. 7). The antiformal stack of model M7 developed in a piggy-back sequence with a minor back rotation of the early thrusts. The differences between models M6 (consisting of a sand layer with constant thickness) and M7 (the sand layer thickness decreases) are probably due to the decreasing resistance to propagation of the deformation front in model M7.

The decreasing thickness of the sand layers in models M5-a and M5-b (Figs. 14 and 15) favors faster propagation of the deformation front. This feature can be observed by comparing model M5-a (Fig. 14b) with models M1, M2 and M3 (Figs. 7b, $9 \mathrm{~b}$ and $11 \mathrm{c}$ ) at $30 \%$ shortening. The relatively small amount of vertical strain in front of the backstop (Fig. 14c), which in other models has produced a steep surface slope (Davis et al. 1983), results from the lower resistance to displacement of the deformation front. As a consequence, only the youngest ramp anticline that impinges on the foreland obstacle produces an antiformal stack (forethrusts 2, 3 and 4, Fig. 14c; and forethrusts 3, 4 and 5, Fig. 15c). Deformation higher than the $53 \%$ shortening of models M5 and M7 would likely transform the entire thrust system into an antiformal stack, pushing the oldest thrusts over the younger ones.

The experiments also show that a deformable sand backstop strongly influences the geometry of thrust systems. The presence of a sand backstop reduces the strong back rotation of the oldest thrusts in the hinterland, which is common in the experiments using rigid backstops (compare Figs. $7 \mathrm{~d}$ and 8d or Figs. 9d and 10d). During progressive shortening, the sand backstop becomes involved in the deformation through nucleation of backthrusts.

Model M3-b (Figs. 12d, e), which has produced the best antiformal stack simulation, demonstrates that its formation requires some amount of backstop-edge effects. This fact confirms the analysis made by Byrne et al. (1993) about backstops within a forearc at subduction zones. They concluded that backstops are stronger than the rocks lying further trenchwards, deform little but may influence the kinematics of the trench rocks. Thus, the sand backstop should represent a much better equivalent for a natural backstop than the rigid moving wall.

\section{CONCLUSIONS}

From the above results, several conclusions may be drawn with respect to development of antiformal stacks:

(1) Antiformal stacks form when there is an impediment to the progressive evolution of a forwardbreaking thrust system. This impediment may be related either to the presence of an obstacle in the foreland or to a high friction along the basal detachment. In nature, obstacles could be a ramp in a crystalline detachment in the internal parts of orogens, or basement highs during tectonic inversion.

(2) Antiformal stacks develop in two different ways:

(a) from an initial thrust system undergoing a piggy-back evolution until an obstacle blocks the deformation front, causing reactivation of thrusts in the hinterland and further convergence of branch lines (models M1, M2, M4, M5 and M7);

(b) from a cyclic process of nucleation of individual thrusts in the foreland, intense back rotation associated with vertical strain, formation of new thrusts and convergence of branch lines (models M3 and M6). 
(3) The interruption of the piggy-back thrust sequence causes synchronous thrusting in both foreland and hinterland.

(4) A variation in the obstacle geometry only changes the geometry of the antiformal stack, but does not modify the deformation processes.

(5) A small slope $\left(5^{\circ}\right)$ of the basal detachment produces geometric differences in the thrust system only when the initial sand layer thickness decreases towards the foreland.

(6) The use of a deformable sand backstop reveals that caution should be taken in using a moving wall as a rigid backstop in experiments. The rigidity of the backstop may induce an abnormal vertical strain.

(7) Model M3-b (Figs. 12d, e) which produced the best simulation of an antiformal stack evolution, suggests that antiformal stacks result from a combination of the following boundary conditions: a) the presence of an obstacle in the foreland, b) a high deformation rate (i.e. a large number of faults form with a small fault spacing, due to thin sand layers) and c) an edge effect in the hinterland of the thrust system, caused by a deformable backstop.

\section{ACKNOWLEDGEMENTS}

I thank the Universidade Federal de Ouro Preto for providing financial assistance through a research studentship to Juliano Efigênio Ferreira. I am greatly indebted to Gary Karner and João Hippertt for useful suggestions and careful correction of the English.

\section{REFERENCES}

Bally AJ, Gordy PL \& Stewart GA. 1966. Structure, seismic data and orogenic evolution of the Southern Canadian Rockies. Bull Canad Petrol Geol 14: 337-381.

BOyer SE. 1978. Structure and origin of the Grandfather Mountain window, North Carolina. Ph.D. thesis. John Hopkins University.
BOYER SE. 1992. Geometric evidence for synchronous thrusting in the southern Alberta and northwest Montana thrust belt. In Thrust Tectonics, eds. KR McCLAY. London, Chapman and Hall, p. 377-390.

Boyer SE \& Elliott D. 1982. Thrust systems. Am Ass Petrol Geol Bull 66: 1196-1230.

Byrne DS, WANG W \& Davis D. 1993. Mechanical role of backstops in the growth of forearcs. Tectonics, 12: 123-144.

DAHLEN FA. 1990. Critical taper model of fold-andthrust belts and accretionary wedges. An Rev Earth Plan Sci 18: 55-99.

Dahlen FA, Suppe J \& Davis D. 1984. Mechanics of fold-and-thrust belts and accretionary wedges: Cohesive Coulomb theory. J Geophys Res 89: 10,08710,101 .

DAhLstrom CDA. 1969. Balanced cross-section. Canad J Earth Sci 6: 743-757.

Davis D, Suppe J \& Dahlen FA. 1983. Mechanics of fold-and-thrust belts and accretionary wedges. $J$ Geophys Res 94: 10347-54.

Elliott D \& Johnson MRW. 1980. Structural evolution in the northern part of the Moine thrust belt, NW Scotland. $R$ S Edinburgh Trans 71: 69-96.

HAtcher RD \& Hooper RJ. 1992. Evolution of crystalline thrust sheets in the internal parts of mountain chains. In Thrust Tectonics, eds. KR McClay. London, Chapman and Hall, p. 217-233.

Hubbert MK. 1937. Theory of scale models as applied to the study of geologic structures. Geol Soc Am Bull 48: $1459-1520$.

Huiqi L, McClay KR \& Powell D. 1992. Physical models of thrust wedges. In Thrust Tectonics, eds. KR McClay. London, Chapman and Hall, p. 7181

JADOON IAK, LAWRENCE RD \& LILlEE RJ. 1992. Balanced and retrodeformed geological cross-section from the frontal Sulaiman Lobe, Pakistan: Duplex development in thick strata along the western margin of the Indian Plate. In Thrust Tectonics, eds. KR McClay. London, Chapman and Hall, p. 343-357. 
MarshaK S, Wilkerson MS \& Hsui AT. 1992. Generation of curved fold-thrust belts: Insight from simple physical and analytical models. In Thrust Tectonics eds. KR McClay. London, Chapman and Hall, p. 83-92.

MCClay KR. 1990. Extensional fault systems in sedimentary basins: a review of analogue model studies. Marine Petrol Geol 7: 206-233.

McClay KR. 1992. Glossary of thrust tectonics terms. In Thrust Tectonics eds. KR McClay. London, Chapman and Hall, p. 419-433.

MCClay KR \& ElLis PG. 1987. Analogue models of extensional fault geometries. In Continental Extensional Tectonics, eds MP Coward, JF Dewey \& PL Hancock. Geol Soc Special Publication 28: 109125 .

McClay KR \& ScotT AD. 1991. Experimental models of hangingwall deformation in ramp-flat listric extensional fault systems. Tectonophys 188: 85-96.

Mitra S. 1986. Duplex structures and imbricate thrust systems: Geometry, structural position, and hydrocarbon potential. Am Ass Petrol Geol Bull Bulletin 70: $1087-1112$.
Mosar J \& Suppe J. 1992. Role of shear in faultpropagation folding. In Thrust Tectonics, eds. KR MCClay. London, Chapman and Hall, p. 123-132.

Mulugeta G \& Koyi H. 1992. Episodic accretion and strain partitioning in a model sand wedge. Tectonophys 202: 319-333.

MuÑoz JA. 1992. Evolution of a continental collision belt: ECORS-Pyrenees crustal balanced crosssection. In Thrust Tectonics, eds. KR McClay. London, Chapman and Hall p. 235-246.

Suppe J, CHOU GT \& Hook SC. 1992. Rates of folding and faulting determined from growth strata. In Thrust Tectonics, eds. KR McClay. London, Chapman and Hall, p. 105-122.

Vendeville B, Cobbold PR, Davy P, Brun JP \& Choukroune P. 1987. Physical models of extensional tectonics at various scales. In Continental Extensional Tectonics, eds. MP COWARD, JF DeWEY \& PL Hancock, Geol Soc Special Publication 28: 95-107. 